\title{
Brief Review on the Memory Types and their Location and Function
}

ISSN: 2639-0612

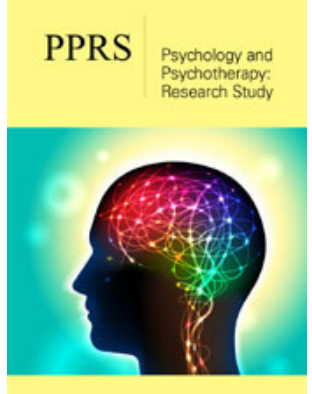

*Corresponding author: Behzad Saberi, Medical Research, Iran

Submission: 侮 August 02, 2021

Published: 监September 16, 2021

Volume 5 - Issue 1

How to cite this article: Behzad Saberi. Brief Review on the Memory Types and their Location and Function. Psychol Psychother Res Stud. 5(1). PPRS. 000605. 2021. DOI: 10.31031/PPRS.2021.05.000605

Copyright@ Behzad Saberi, This article is distributed under the terms of the Creative Commons Attribution 4.0 International License, which permits unrestricted use and redistribution provided that the original author and source are credited.

\author{
Behzad Saberi* \\ Medical Research, Iran
}

\section{Introduction}

Memory is an important part of brain function which can be affected by various pathologies. Studying about memory is important in both basic and clinical science. This is a brief review on the memory types and their location and function.

Keywords: Memory types; Anatomical location; Function

Body

Memory can be classified into declarative/explicit and nondeclarative/implicit. Declarative/explicit memory can be divided into semantic, episodic and short-term/working memory while nondeclarative/implicit memory can be divided into procedural, conditioning and motor skills/memory [1-3]. Semantic memory is located in parahippocampal gyrus and its function would be world facts remembering. Episodic memory is located in the hippocampus and its function includes the life episodes and events related memory. Short-term/working memory is located in the prefrontal cortex and its function would be information retention for ongoing behavior guidance.

Procedural memory which is located in the striatum will function for tasks remembering and behavioral habits formation. Conditioning memory is anatomically distributed and its function would be associating a stimulus which evokes a response which would be reasonable from a second stimulus. Motor skills/memory which its learning location would be the cerebellum and its storage would happen in the cerebellum and the other part of the brain which is not clearly known maybe in the cortex would function as the motor skills learned memory [4-6].

\section{Conclusion}

It is important for the clinicians to have knowledge about various types of memory and their anatomical location and function so that it can be possible to approach the patients suffering from memory problems better during clinical practice. Also having such knowledge would help to work on basic research studies in the field of memory and related pathologies $[7,8]$.

\section{References}

1. Dickerson BC, Eichenbaum H (2010) The episodic memory system: Neurocircuitry and disorders. Neuropsychopharmacology 35(1): 86-104.

2. Kolb B, Whishaw IQ (2003) Fundamentals of human neuropsychology. Worth Publishers, New York, USA.

3. Kandel ER, Dudai Y, Mayford MR (2014) The molecular and systems biology of memory. Cell 157(1): 163-186. 
4. Duncan J, Owen AM (2000) Common regions of the human frontal lobe recruited by diverse cognitive demands. Trends Neurosci 23(10): 475483.

5. Craver CF (2003) The making of a memory mechanism. J History Biol 36(1): 153-195.

6. Brodziak A, Brewczynski A, Bajor G (2013) Clinical significance of knowledge about the structure, function, and impairments of working memory. Medical Science Monitor 19: 327-338.
7. Binder JR, Desai RH (2011) The neurobiology of semantic memory. Trends Cogn Sci 15(11): 527-536.

8. Baddeley AD (2007) Working memory, thought, and action. Oxford University Press, London, UK

For possible submissions Click below: 